\title{
Maternal and neonatal outcome of reverse breech extraction of an impacted fetal head during caesarean section in advanced stage of labour: a retrospective cohort study
}

\author{
Franziska Lenz ${ }^{1}$, Nina Kimmich², Roland Zimmermann² and Martina Kreft ${ }^{2 *}$
}

\begin{abstract}
Background: Caesarean section with extraction of a deeply impacted fetal head is technically challenging and is associated with serious maternal and neonatal complications. The purpose of the study was to identify risks and evaluate selected outcome parameters associated with difficult fetal head extraction during caesarean section in advanced labour comparing two different extraction techniques (head pushing vs. reverse breech).

Methods: This retrospective cohort study was conducted at the Division of Obstetrics in a tertiary care hospital in Zurich, Switzerland. 629 women at term with a singleton pregnancy in cephalic presentation during advanced intrapartum caesarean section from December 2012 until December 2016 were evaluated. Primary outcome was the incidence of uterine incision extensions. Secondary outcomes were other selected maternal and neonatal outcome parameters. Data analysis was performed using SPSS with Mann-Whitney $U$ independent sampling test and two-tailed Fisher's exact test $(p<0.01)$.

Results: Difficult fetal head extractions are associated with significantly elevated maternal and neonatal risks. When performed by reverse breech technique, significant lower rates of extensions of the uterine incision, shorter operation times and less operative blood loss were identified compared to the head pushing method. No statistically significant differences for the neonatal outcomes were described so far. However, among the group of difficult fetal delivery with the head pushing method two neonates had perinatal skull fractures, with one of those resulting in neonatal death.

Conclusions: The head pushing method is associated with higher maternal morbidity than the reverse breech method for extraction of a deeply engaged fetus during intrapartum caesarean section in advanced stage of labour.
\end{abstract}

Keywords: Impacted fetal head, Reverse breech extraction, Caesarean section, Advanced stage of labour

\section{Background}

Performing a caesarean section with extraction of a deeply impacted fetal head out of the maternal pelvis is technically challenging even for experienced obstetricians. The difficulty for the surgeon is to disengage the impacted head by hand due to a lack of space between the muscular and bony maternal pelvis and the deeply impacted fetal head [1]. This procedure is associated with elevated maternal risks including unintentional

\footnotetext{
* Correspondence: Martina.Kreft@usz.ch

2Division of Obstetrics, University Hospital Zurich, Zurich, Switzerland Full list of author information is available at the end of the article
}

extensions of the uterine incision into the vascular broad ligament, prolonged operation times and postpartum haemorrhage [2-8]. Furthermore, serious neonatal complications, for instance skull injuries causing cerebral haemorrhage and newborn hypoxia that result in higher neonatal admission rates are described $[1,7,9]$.

The constantly rising rates of intrapartum caesarean sections especially at full cervical dilation highlight the increasing importance of a skilful technique to deliver the fetus [10]. Thus, there are different methods of fetal delivery known in caesarean sections at advanced stage of labour. The conventional fetal extraction by lifting the head out of the maternal pelvis by the surgeon's hand

(c) The Author(s). 2019 Open Access This article is distributed under the terms of the Creative Commons Attribution 4.0 International License (http://creativecommons.org/licenses/by/4.0/), which permits unrestricted use, distribution, and reproduction in any medium, provided you give appropriate credit to the original author(s) and the source, provide a link to the Creative Commons license, and indicate if changes were made. The Creative Commons Public Domain Dedication waiver (http://creativecommons.org/publicdomain/zero/1.0/) applies to the data made available in this article, unless otherwise stated. 
(head pushing) is often assisted by vaginal dislodge and exerts considerable force on the fetal head $[5,6,11]$. As an alternative to the head pushing technique, the pull method with fetal delivery via reverse breech was first described by Patwardhan 1957 [12] and is predominantly practiced in developing countries [5, 7-9, 13, 14]. The reverse breech technique was adopted according to the original description of Patwardhan [12] and established at our hospital for difficult fetal extractions during caesarean section in advanced labour since December 2014.

The objective of this study was to investigate selected maternal and neonatal outcome parameters of difficult deliveries with impacted fetal head during caesarean sections in obstructed labour with regard to different techniques of fetal extraction (head pushing vs. reverse breech). Therefore, we first identified obstetrical, maternal and neonatal risks that led to difficult fetal extractions. Second, we evaluated the outcomes associated with uncomplicated compared to difficult fetal extractions. Third, we examined the differences between the head pushing and the reverse breech method. As the primary outcome we analysed the incidence of uterine incision extensions, as secondary outcomes we selected maternal morbidities including operation time and operative blood loss as well as neonatal parameters.

\section{Methods}

This retrospective study was conducted at the Division of Obstetrics in a tertiary care hospital in Zurich, Switzerland. A total number of 11,209 deliveries were recorded at our department between the observed time periods from December 2012 to December 2016. Among these deliveries 4928 caesarean sections were performed. We analysed all women at term ( $\geq 37+0$ weeks of pregnancy) with a singleton pregnancy in cephalic presentation from our obstetric database, which required an intrapartum caesarean section at cervical dilation $\geq 7 \mathrm{~cm}$ between December 2012 and December 2016. The excluding criteria were multiple pregnancies, fetal anomalies, preterm delivery and fetal presentation other than cephalic. The final study population consisted of 629 women.

Obstetrical, maternal and fetal baseline criteria and outcomes were recorded and compared between groups of uncomplicated and difficult fetal extractions. The latter group was subdivided into deliveries performed by either the conventional head pushing method $(n=82)$ or the reverse breech technique $(n=55)$.

Cephalic malpresentation, as one of the baseline criteria, was defined as any fetal head presentation other than flexed occipito anterior. A larger fetal head circumference is determined to be a predictor for an unplanned caesarean section [15]. Lipschuetz et al. showed that a head circumference of $>35 \mathrm{~cm}$ increases the risk of a prolonged second stage of labour and is associated with a higher risk for an unplanned caesarean section [16]. Therefore, we selected a head circumference $>35 \mathrm{~cm}$ to evaluate a difference between the uncomplicated and difficult fetal extraction group.

The incision-delivery time is defined as the time interval between skin incision and delivery of the baby and the uterotomy-delivery time is understood to be the interval between uterus incision and the delivery of the baby. Both time intervals are routinely measured and documented when performing a caesarean section at our department.

A fetal extraction was defined to be difficult, when either T-incisions or transvaginal head pushing manoeuvres were performed, if the reverse breech extraction was necessary due to a failed fetal extraction caused by an impacted fetal head, or if declared as a difficult extraction in the surgical report (done by the surgeon just after having performed the caesarean section). Those information can be extracted out of our obstetric database, an in-house computerised patient data and clinical information system which contains the complete maternal, fetal and obstetrical data of every woman.

The conventional head pushing method during caesarean section was performed by lifting the fetal head out of the maternal pelvis by the surgeon's hand. If the surgeon was not able to lift the head, vaginal dislodge by the help of an assistant's hand or an inserted silicone cup (normally used for vacuum deliveries) was additionally performed, so the surgeon could finally deliver the fetal head through the uterine incision [6].

In comparison, the reverse breech extraction (pull method) is illustrated in Fig. 1, here with the fetus in occiput posterior position. After uterine incision first the fetal arms have to be extracted, than the surgeon grasps the feet and delivers both legs that are located in the fundal uterine region. After extraction of the fetal body by pulling symmetrically on both legs, sometimes supported by fundal pressure, the head can be easily disengaged from the maternal pelvis by an unscrewing manoeuvre $[9,17]$. It should be taken into account that the fetal head when entering the maternal pelvis is positioned in a transverse diameter and rotates like a key in a keyhole from a transverse to an anterior posterior diameter. During caesarean section when the head is deeply impacted the process must be performed exactly backwards. Therefore, the head should be carefully unscrewed to the transverse diameter and possibly flexed so that the flexion point reaches the middle of the uterotomy. As the head is deeply impacted inside the maternal pelvis, it is initially not possible to grasp head and shoulders simultaneously. Therefore, when performing the reverse breech extraction the unscrewing is been done by first grasping the body and shoulders simultaneously and rotate the fetus very carefully. As soon as the 

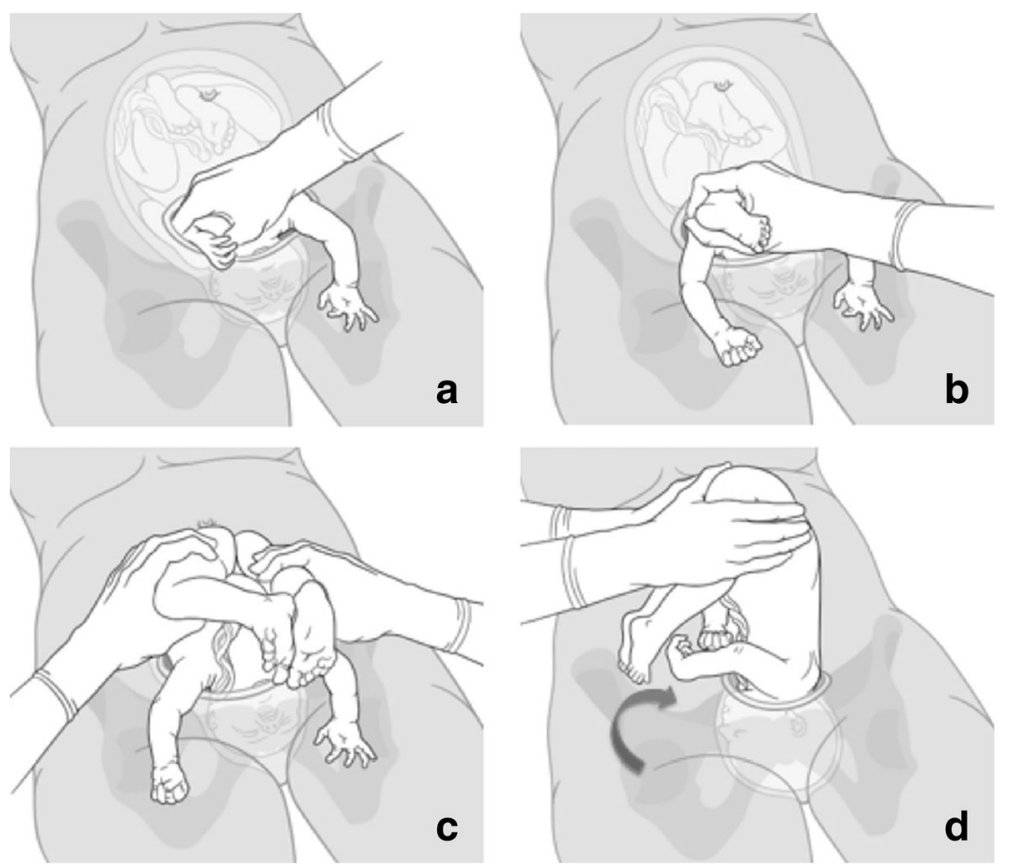

Fig. 1 Reverse breech technique (occiput posterior position). a extract both fetal arms; b grasp the fetal foot with extraction of a leg; c extraction of the fetal body by pulling on both legs; $\mathbf{d}$ delivery of the fetal head by simultaneously screwing on the body and the shoulders

fetal head can be reached, the shoulders and head are being grasped simultaneously so that the whole fetus can easily be delivered out of the uterotomy (or in assistance of Mauriceau-Smellie-Veit manoeuvre). This handling ensures a gentle delivery of the fetus and minimal twisting on the fetal spine.

Figure 2 shows the reverse breech technique in occiput anterior position. The surgeon grasps the babies back with both hands and pulls them gradually to reach the breech. Again, fundal pressure is sometimes helpful to extract the body. Thereafter, the identical unscrewing manoeuvre is applied to extract the head.

At our clinic unplanned caesarean sections are only performed by experienced residents under supervision of a senior consultant. Therefore, there is always an experienced team performing the caesarean section and in terms of difficult fetal extraction the consultant takes over to deliver the baby. Usually the experienced resident performs the surgery and tries to deliver the baby by lifting the head out of the maternal pelvis in case of vertex presentation. In case of difficult fetal extraction, the consultant takes over and first tries again to deliver the baby by lifting the head first. If the consultant is not able to get one hand under the fetal's head, he then immediately grasps the fetal legs and performs a reverse breech delivery since the introduction of the new technique in December 2014.

The data was analysed using SPSS version 23 (IBM, Armonk, NY, USA). The Mann-Whitney U independent sampling test was used for continuous and the two-tailed Fisher's exact test for categorical variables with $p<0.01$ considered to indicate statistical significance.

\section{Results}

When comparing uncomplicated and difficult fetal extractions a statistically significant difference in obstetrical and neonatal baseline criteria was seen in cervical dilation, rate of cephalic malpresentation and neonatal head circumference (Table 1).

Selected outcome parameters of an uncomplicated and difficult fetal delivery were compared. The comparison showed statistically significant differences between both groups, which can be seen in (Table 2).

Regarding the analysis of difficult fetal extractions by the two different methods of delivery (head pushing vs. reverse breech) no significant changes in baseline criteria could be identified (Table 3).

Among the group of difficult extractions performed by reverse breech method we identified highly significant lower rates of extensions of the uterine incision, a shorter operation time and less blood loss compared to the conventional head pushing method during caesarean sections in advanced stage of labour (Table 4).

Between the groups there were no statistically significant differences with regard to fetal outcome, however all parameters tend to benefit from the reverse breech method. Concerning the neonatal outcome, there was only one single admission to the neonatal intensive care 

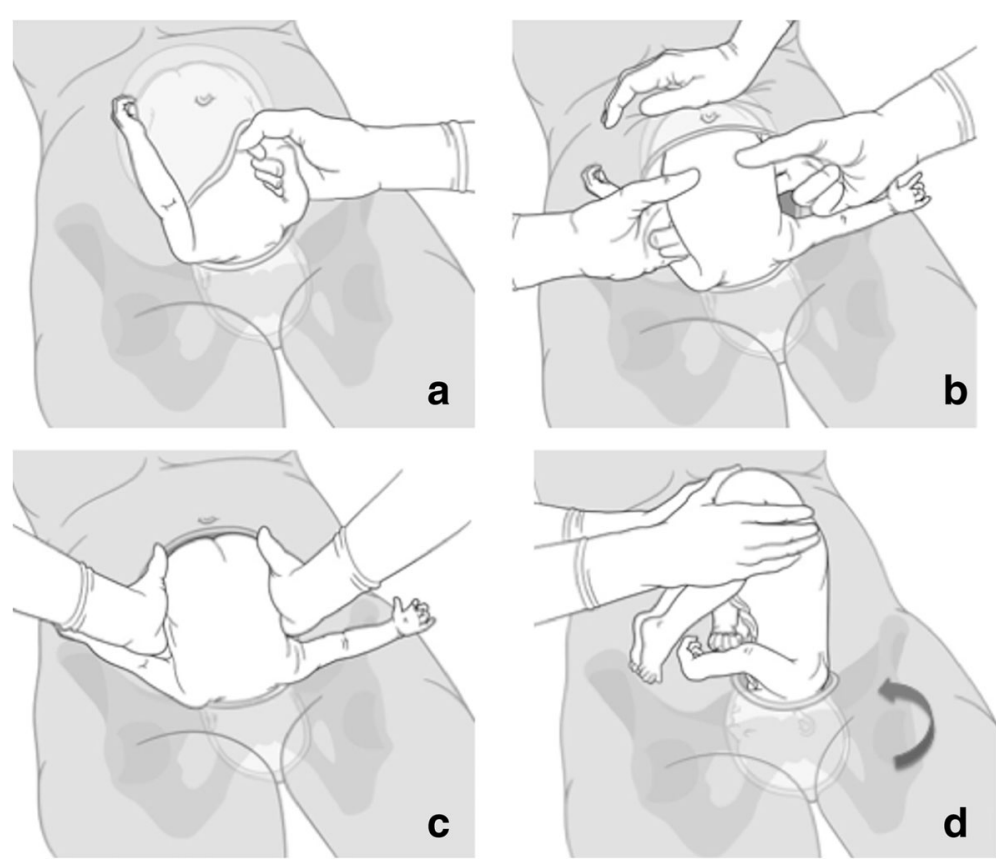

Fig. 2 Reverse breech technique (occiput anterior position). a extract both fetal arms; b grasp the fetal trunk / hip with both hands; c extraction of the fetal body by pulling on the hips with pressure on the fundus; $\mathbf{d}$ delivery of the fetal head by simultaneously screwing on the body and the shoulders

unit after reverse breech extraction due to acute respiratory distress syndrome. However, one fetal humours fracture was caused by a reverse breech extraction in occiput posterior position when the baby's arm was hidden behind the back and it was technically impossible to extract it first. In this case no indication of primary admission to the neonatal intensive care unit was given. Among the group of difficult fetal delivery with the head pushing method two neonatal admissions were necessary due to perinatal skull fractures, with one of those resulting in neonatal death.

\section{Discussion}

The deeply impacted fetal head is an obstetrical emergency situation, which requires a secure delivery technique to prevent undesirable maternal and neonatal consequences $[1,13]$.

Regarding a difficult fetal delivery, head pushing is the most commonly practised technique. However, reverse breech extraction has gradually been given higher priority, not only in developing countries with longer periods of second stage labour, but also in higher resource settings $[1,5,6,18,19]$. Rising rates of intrapartum caesarean sections and the presented significant differences of an uncomplicated compared to a difficult delivery highlight the importance of a safe intrapartum care for mother and child $[6,10]$. On one hand, difficult fetal extractions are associated with an increased maternal risk of postpartum haemorrhage with elevated blood loss and higher delta haemoglobin pre- and postpartum $[9,13]$. This increased risk results from a prolonged incision-

Table 1 Baseline criteria comparing uncomplicated and difficult fetal extraction

\begin{tabular}{lllll}
\hline & baseline criteria & group 1: & group 2: & $p$-value \\
& mean \pm SD $/ \mathrm{n}(\%)$ & uncomplicated $(n=492)$ & difficult $(n=137)$ \\
\hline obstetrical & gestational age (in weeks) & $39.8 \pm 1.1$ & $39.64 \pm 1.1$ & $103(75.2)$ \\
& full cervical dilation $(10 \mathrm{~cm})$ & $310(63.0)$ & $91(66.4)$ & $\mathbf{0 . 0 3}$ \\
& cephalic malpresentation & $260(52.9)$ & $31.6 \pm 5.1$ & $\mathbf{0 . 0 0 5 ^ { * }}$ \\
maternal & age (in years) & $31.7 \pm 5.0$ & $23.5 \pm 4.7$ & 0.934 \\
& BMl before pregnancy (in $\left.\mathrm{kg} / \mathrm{m}^{2}\right)$ & $22.8 \pm 4.0$ & $3453.2 \pm 420.9$ & 0.075 \\
neonatal & weight (in g) & $3555.9 \pm 450.8$ & $53(38.7)$ & 0.02 \\
& head circumference $>35 \mathrm{~cm}$ & $267(54.3)$ & $\mathbf{0 . 0 0 1}$ & \\
\hline
\end{tabular}

SD standard deviation, $n$ (\%) number (per cent), BMI body mass index, ${ }^{*}$ significant statistical difference between the groups $(p<0.01)$ 
Table 2 Outcome parameters comparing uncomplicated and difficult fetal extraction

\begin{tabular}{|c|c|c|c|c|}
\hline & $\begin{array}{l}\text { outcome parameters } \\
\text { mean } \pm \text { SD / } \mathrm{n}(\%)\end{array}$ & $\begin{array}{l}\text { group 1: } \\
\text { uncomplicated }(n=492)\end{array}$ & $\begin{array}{l}\text { group 2: } \\
\text { difficult }(n=137)\end{array}$ & p-value \\
\hline \multirow[t]{4}{*}{ obstetrical } & operation time (in min) & $32.2 \pm 11.1$ & $42.2 \pm 17.7$ & $<0.001^{*}$ \\
\hline & incision-delivery time (in min) & $4.6 \pm 2.0$ & $6.9 \pm 2.9$ & $<0.001^{*}$ \\
\hline & uterotomy-delivery time (in min) & $1.3 \pm 0.8$ & $2.8 \pm 1.5$ & $<0.001^{*}$ \\
\hline & additional instrumental delivery & $3(0.6)$ & $7(5.1 \%)$ & $0.003^{*}$ \\
\hline \multirow[t]{4}{*}{ maternal } & blood loss (in ml) & $556 \pm 229.9$ & $652.2 \pm 322.9$ & $<0.001^{*}$ \\
\hline & $\begin{array}{l}\text { delta haemoglobin pre-/postpartum } \\
\text { (in } \mathrm{g} / \mathrm{l} \text { ) }\end{array}$ & $21.4 \pm 11.6$ & $25.8 \pm 12.2$ & $<0.001^{*}$ \\
\hline & extensions of the uterine incision & $68(13.8)$ & $34(24.8)$ & $0.004^{*}$ \\
\hline & T-incisions & 0 & $7(5.1)$ & $<0.001^{*}$ \\
\hline \multirow[t]{4}{*}{ neonatal } & umbilical arterial $\mathrm{pH}<7.15$ & $10(2.0)$ & $12(8.8)$ & $<0.001^{*}$ \\
\hline & Apgar score at five minutes $<7$ & $5(1.0)$ & $3(2.2)$ & 0.381 \\
\hline & admissions to the neonatal unit & $1(0.2)$ & $3(2.2)$ & 0.01 \\
\hline & death & 0 & $1(0.7)$ & 0.22 \\
\hline
\end{tabular}

SD standard deviation, $n(\%)$ number (per cent), BMI body mass index, * significant statistical difference between the groups $(p<0.01)$

delivery time, uterotomy-delivery time, total operation time and are caused by a higher rate of extensions of the uterine wound, T-incisions and additional instrumental support. On the other hand, difficult fetal extraction leads to severe neonatal consequences such as significantly higher rates of neonatal umbilical arterial $\mathrm{pH}<7.15$ and admissions to the neonatal care unit $[1,7,9]$. Therefore, it is important to incorporate alternative methods of fetal delivery into the daily obstetrical routine for a better outcome for mother and child.

With the introduction of the reverse breech method in caesarean sections for obstructed labour in 2014 we were able to observe less maternal complications with emphasis on a significantly lower rate of extensions of the uterine incision, which has been defined as the primary outcome $(p<0.001)$. Similar results regarding a higher rate of extensions of the uterine incision in caesarean sections performing fetal extraction via push technique were found in earlier publications $[1,5,6,8$, $9,14,18,20]$. A shorter operation time and less blood loss compared to the head pushing method were also evaluated. The present findings correlate with the results of Sethuram et al. [6], Berhan \& Berhan [7], and Veisi et al. [13] describing a significant rise of the duration of surgery and of uterine wound extensions, plus higher blood loss in the head pushing group among difficult fetal extractions by comparing the two mentioned delivery techniques.

No statistically significant findings in the present analysis were identified regarding neonatal outcome when comparing the two extraction methods. Compared to the conventional cephalic delivery, where two skull injuries were found that resulted in severe neonatal complications and even one in neonatal death, none were detected in the reverse breech group. Berhan \& Berhan [7] report an increase of overall perinatal mortality in the head pushing group when compared to reverse breech. Concerning fetal birth trauma Fasubaa et al. [9], Veisi et al. [13], and Bastani et al. [20] did not describe any significant fetal differences between the two investigated extraction techniques. In contrast to the present data and former studies [8, 13, 14, 20] Fasubaa et al. [9]

Table 3 Comparison of baseline criteria of difficult fetal delivery regarding the technique

\begin{tabular}{lllll}
\hline & baseline criteria & group 2a: & group 2b: & p-value \\
& mean \pm SD / $\mathrm{n}(\%)$ & head pushing $(n=82)$ & $39.5 \pm 1.1$ & 0.31 \\
\hline obstetrical & gestational age (in weeks) & $39.7 \pm 1.0$ & $45(81.8)$ & 0.162 \\
& full cervical dilation $(10 \mathrm{~cm})$ & $58(70.7)$ & $43(78.1)$ & $31.6 \pm 5.1$ \\
& cephalic malpresentation & $48(58.5)$ & $22.7 \pm 2.9$ & 0.026 \\
maternal & age (in years) & $31.7 \pm 5.0$ & $3411 \pm 473$ & 0.934 \\
& BMl before pregnancy (in $\left.\mathrm{kg} / \mathrm{m}^{2}\right)$ & $23.9 \pm 5.4$ & $20(36.4)$ & 0.359 \\
neonatal & weight (in g) & $3481.5 \pm 382.5$ & & 0.722 \\
& head circumference $>35 \mathrm{~cm}$ & $33(40.2)$ & &
\end{tabular}

SD standard deviation, $n$ (\%) number (per cent), BMI body mass index 
Table 4 Comparison of outcome parameters of difficult fetal delivery regarding the technique

\begin{tabular}{|c|c|c|c|c|}
\hline & $\begin{array}{l}\text { outcome parameters } \\
\text { mean } \pm \text { SD / } \mathrm{n}(\%)\end{array}$ & $\begin{array}{l}\text { group 2a: } \\
\text { head pushing }(n=82)\end{array}$ & $\begin{array}{l}\text { group } 2 \mathrm{~b} \text { : } \\
\text { reverse breech }(n=55)\end{array}$ & $p$-value \\
\hline \multirow[t]{4}{*}{ obstetrical } & operation time (in min) & $44.8 \pm 16.7$ & $38.3 \pm 18.4$ & $0.006^{*}$ \\
\hline & incision-delivery time (in min) & $7.0 \pm 3.2$ & $6.7 \pm 2.5$ & 0.979 \\
\hline & uterotomy-delivery time (in min) & $2.7 \pm 1.5$ & $3.1 \pm 1.5$ & 0.085 \\
\hline & additional instrumental delivery & $7(8.5)$ & 0 & 0.041 \\
\hline \multirow[t]{4}{*}{ maternal } & operative blood loss (in ml) & $712.2 \pm 375.0$ & $562.7 \pm 195.1$ & $0.009^{*}$ \\
\hline & delta haemoglobin pre-/postpartum (in g/l) & $26.8 \pm 12.9$ & $24.2 \pm 10.9$ & 0.257 \\
\hline & extensions of the uterine incision & $29(35.4)$ & $5(9.1)$ & $<0.001^{*}$ \\
\hline & T-incisions & $5(6.1)$ & $2(3.6)$ & 0.702 \\
\hline \multirow[t]{4}{*}{ neonatal } & umbilical arterial $\mathrm{pH}<7.15$ & $8(9.8)$ & $4(7.3)$ & 0.768 \\
\hline & Apgar score at five minutes $<7$ & $3(3.7)$ & 0 & 0.274 \\
\hline & transmissions to the neonatology unit & $2(2.4)$ & $1(1.8)$ & 1.0 \\
\hline & death & $1(1.2)$ & 0 & 1.0 \\
\hline
\end{tabular}

$S D$ standard deviation, $n$ (\%) number (per cent), BMI body mass index, ${ }^{*}$ significant statistical difference between the groups $(p<0.01)$

could also prove significant differences in fetal Apgar scores at five minutes and in the rates of neonatal death. However, similar to the results of former studies one extremity fracture caused by reverse breech extraction was described $[6,7,13,18]$. This fact indicates the need for an even more skilful and gentle approach in the future.

The present baseline criteria of difficult fetal extractions in general showed that the risk of having a difficult fetal extraction during caesarean section rises with an increase of cervical dilation, especially when fully dilated. Furthermore, fetuses with larger head circumferences $>35 \mathrm{~cm}$ have a higher risk to not enter the deep pelvis in intrapartum caesarean sections most likely caused by cephalopelvic disproportion and therefore have a lower risk of being impacted in the maternal pelvis. On the other hand, fetuses with a head circumference below $35 \mathrm{~cm}$ or with cephalic malpresentation are more likely to have a difficult extraction caused by impaction in the maternal pelvis.

When comparing the different extraction methods (head pushing vs. reverse breech) significant differences in maternal outcome can be seen. In fact, prolonged labour increases the thinning of the lower uterine segment by an engaged fetal head and elevates the risk of damage to the uterine vessels and the lower urinary tract by cephalic delivery via head pushing method $[3,7,13]$. A highly significant reduced rate of extensions of the uterine incision may be explained by the more gentle delivery technique of reverse breech, which also results in a shorter operation time for repair, less blood loss due to less lacerations in the broad ligaments and less cervical lacerations, which has also been discussed in former studies [1, 3, 7, 13]. A shorter surgical duration also prevents a prolonged anaesthesia with potential side effects [12].
Regarding the neonatal outcome the present data showed less morbidity after reverse breech extraction compared to the head pushing method for obstructed labour. All outcomes show a tendency to a better effect in the reverse breech group. Further research with a higher number of cases is required to determine a significant difference definitely. Despite the lack of statistical significance the severity of neonatal morbidity shows clinical relevance. Originally, the reverse breech technique was also developed to improve the neonatal outcome, with the assumption that mainly tensile forces were acting and therefore the pressure on the child's head could be reduced [9]. Thus, we suggest that the reverse breech technique should initially be considered in all intrapartum caesarean sections with a lack of space between the maternal pelvis and the impacted fetal head or when the anterior fetal arm has already dropped out after the uterine incision.

The 55 cases of reverse breech extraction had been analysed since the introduction of the new modified delivery method at our clinic. During this time the initially inexperienced obstetric staff had to pass a certain training period with appropriate written and practical instructions of reverse breech technique. At our institution we have different practical models of simulation training already. Desperate Debra $^{\circ}$ is one of those models to train difficult head extraction during caesarean section. A vaginal examination is possible to identify the fetal's head position. The model allows rotation and flexion of the fetal head after insertion of a hand into the caesarean incision and between the fetal head and uterus. Because of missing shoulders and legs the reverse breech technique cannot be trained with this model. The development of a special training tool for reverse breech technique would improve the teaching and 
facilitate instructions to ensure a high level of confidence in a low-stress environment. Nevertheless, in order to introduce the reverse breech technique at our clinic we used other training tools for teaching such as lectures, hand-out material and own video tutorials made by the head of department while performing reverse breech technique by himself.

In the future, it will be necessary to further establish this pull technique in current daily practice and to intensify the training especially for inexperienced obstetrical staff to ensure safe intrapartum care and prove statistical relevance of the neonatal outcome. Training tools such as objective structured assessment tools, case-based discussions, video analysis and mini-clinical examinations for complex caesarean sections in obstructed labour are mandatory to improve the trainees' confidence and establish a clinical standard [6].

\section{Strengths}

The present study was one of very few conducted in a tertiary hospital with validated standards compared to the majority of former studies taken from obstetric units in lower-resource settings or performed in developing countries. Evidence is limited, however with 629 included participants analysed during an observation period of 4 years, our representative trail has a large sample size of evaluated cases. A remarkable number of significances calculated from 55 cases of reverse breech extractions were found despite the fact that the staff still had to pass a learning period for this new modified technique.

\section{Limitations}

The definition of a truly engaged fetal head resulting in a difficult extraction is subjective and always depends on the surgeon's description. In this retrospective study two techniques of fetal extraction during caesarean section were analysed, however the risk of bias due to sometimes remarkable differences in experience, skills, and knowledge of the surgeons have to be taken into consideration. Additionally, when the reverse breech technique was first established at our clinic at the end of 2014, the obstetricians had to pass an individual learning curve to adapt to this new technique. Besides, no data of ultrasound during labour (for instance measurements of the angle of progression) were analysed to prove, whether an instrumental vaginal delivery would have been the better choice than a caesarean section in those cases where the cervix was fully dilated. Another limitation is a comparatively small number of rare outcomes such as fetal injuries, neonatal admissions to the intensive care unit or early neonatal death. To observe a statistically significant difference in neonatal outcome a much larger sample size is needed.

\section{Conclusions}

The reverse breech method is associated with less maternal morbidity than the head pushing method for extraction of a deeply impacted fetal head during intrapartum caesarean delivery. The beneficial maternal-fetal results of performing the reverse breech procedure indicate that it is a reliable alternative to the standard head pushing method and should preferably be used in deeply impacted fetal head situations during caesarean section in advanced labour. Further randomised controlled trials are required to power especially the assessment of neonatal outcome and to confirm a suspected superiority of reverse breech method for both mother and child.

\section{Abbreviations \\ BMI: Body mass index; n: Number; SD: Standard deviation \\ Acknowledgments \\ Not applicable. \\ Funding \\ None. \\ Availability of data and materials \\ The data analysed during this study are included in the tables in this published article. The datasets used during the current study are available from the corresponding author on reasonable request. \\ Authors' contributions \\ FL performed the study design, literature search, data extraction, retrospective analysis, preparation and revision of the manuscript. RZ introduced the reverse breech extraction method, wrote a standard operating procedure for the department and trained people in the delivery ward. NK and RZ contributed to the overall quality assessment and revision of the final manuscript. MK helped in the study design and data extraction, did most of the statistical analysis and was a major contributor in writing and revising the manuscript. All authors read and approved the final manuscript.}

Ethics approval and consent to participate

This study was approved by the Ethical Board of Zurich/Switzerland under the registration number BASEC-No. 2016-02244 (date of approval January 27th 2017).

\section{Consent for publication}

Not applicable.

Competing interests

The authors declare that they have no competing interests.

\section{Publisher's Note}

Springer Nature remains neutral with regard to jurisdictional claims in published maps and institutional affiliations.

\section{Author details}

${ }^{1}$ Department of Obstetrics and Gynaecology, Kantonsspital Baden AG, Baden, Switzerland. ²Division of Obstetrics, University Hospital Zurich, Zurich,

Switzerland.

Received: 5 April 2018 Accepted: 19 March 2019

Published online: 27 March 2019

\section{References}

1. Jeve YB, Navti OB, Konje JC. Comparison of techniques used to deliver a deeply impacted fetal head at full dilation: a systematic review and metaanalysis. BJOG. 2016;123:2226. 
2. Allen VM, O'Connell CM, Baskett TF. Maternal and perinatal morbidity of caesarean delivery at full cervical dilatation compared with caesarean delivery in the first stage of labour. BJOG. 2005;112:986.

3. Sung JF, Daniels KI, Brodzinsky L, El-Sayed YY, Caughey AB, Lyell DJ. Caesarean delivery outcome after a prolonged second stage of labor. Am J of Obstet Gynecol. 2007;197:e1.

4. Lurie S, Raz N, Boaz M, Sadan O, Golan A. Comparison of maternal outcomes from primary cesarean section during the second compared with first stage of labor by indication for the operation. Eur J Obstet Gynecol Reprod Biol. 2014;182:43.

5. Levy R, Chernomoretz T, Appelman Z, Levin D, Or Y, Hagay ZJ. Head pushing versus reverse breech extraction in cases of impacted fetal head during cesarean section. Eur J Obstet Gynecol Reprod Biol. 2005;121:24.

6. Sethuram R, Jamjute P, Kevelighan E. Delivery of the deeply engaged head: a lacuna in training. J Obstet Gynaecol. 2010;30:545.

7. Berhan Y, Berhan A. A meta-analysis of reverse breech extraction to deliver a deeply impacted head during cesarean delivery. Int J Gynaecol Obstet. 2014;124:99.

8. Mukhopadhyay P, Naskar T, Dalui R, Hazra S, Bhattacharya D. Evaluation of Patwardhan's technic - a four year study in a rural teaching hospital. J Obstet Gynecol India. 2005;55:244.

9. Fasubaa OB, Ezechi OC, Orji EO, Ogunniyi SO, Akindele ST, Loto OM, et al. Delivery of the impacted head of the fetus at cesarean section after prolonged obstructed labour: a randomised comparative study of two methods. J Obstet Gynecol. 2002;22:375.

10. Unterscheider J, McMenamin M, Cullinane F. Rising rates of caesarean deliveries at full cervical dilatation: concerning trend. Eur J Obstet Gynaecol Reprod Biol. 2011;157:141.

11. Landesman R, Graber EA. Abdominovaginal delivery: modification of the cesarean section operation to facilitate delivery of the impacted head. Am J Obstet Gynecol. 1984;148:707.

12. Patwardhan BD, Motashaw ND. Caesarean section. J Obstet Gynecol India. 1957:8:1.

13. Veisi F, Zangeneh M, Malekkhosravi S, Rezavand N. Comparison of "push" and "pull" methods for impacted fetal head extraction during cesarean delivery. Int J Gynaecol Obstet. 2012;118:4.

14. Saha PK, Gulati R, Goel P, Tandon R, Huria A. Second stage caesarean section: evaluation of patwardhan technique. J Clin Diagn Res. 2014;8:93.

15. Burke N, Burke G, Breathnach F, McAuliffe F, Morrison JJ, Turner M, et al. Prediction of cesarean delivery in the term nulliparous woman: results from the prospective, multicenter Genesis study. Am J Obstet Gynecol. 2017; 216(6):598.e1

16. Lipschuetz M, Cohen SM, Israel A, Baron J, Porat S, Valsky DV, et al. Sonographic large fetal head circumference and risk of cesarean delivery. Am J Obstet Gynecol. 2018;218(3):339.e1.

17. Fong YF, Arulkumaran S. Breech extraction - an alternative method of delivering a deeply engaged head at cesarean section. Int J Obstet Gynecol. 1997:56:183.

18. Chopra S, Bagga R, Keepanasseril A, Jain V, Kalra J, Suri V. Disengagement of the deeply engaged fetal head during cesarean section in advanced labor: conventional method versus reverse breech extraction. Acta Obstet Gynecol Scand. 2009:88:1163.

19. Frass KA, Al Eryani A, Al-Harazi AH. Reverse breech extraction versus head pushing in caesarean section for obstructed labour. Saudi Med J. 2011;32:1261

20. Bastani P, Pourabolghasem S, Abbasalizadeh F, Motvalli L. Comparison of neonatal and maternal outcomes associated with head-pushing and headpulling methods for impacted fetal head extraction during cesarean delivery. Int J Gynaecol Obstet. 2012;118:1.

Ready to submit your research? Choose BMC and benefit from:

- fast, convenient online submission

- thorough peer review by experienced researchers in your field

- rapid publication on acceptance

- support for research data, including large and complex data types

- gold Open Access which fosters wider collaboration and increased citations

- maximum visibility for your research: over $100 \mathrm{M}$ website views per year

At BMC, research is always in progress.

Learn more biomedcentral.com/submissions 